oxygen." If any meaning is to be attached to these words they surely mean that active oxygen and active hydrogen are present together.

To sum up, I hold that no proof has been given that the lipoid-globulin particles form an oxidase-reducase system, nor that oxidation and reduction play any part in the mode of action of the antisyphilitic remedies in question. Mr. McDonagh must find another foundation for his theories or give better evidence for that which he puts forward.

I am, Sir, yours faithfully,

University College, London, July 18th, 1916. W. M. BAXLISS.

\section{THE CARDIAC DISABILITIES OF SOLDIERS ON ACTIVE SERVICE.}

To the Editor of THE LANCET.

SIR,-I must confess to a feeling of bewilderment not unmixed with dismay at reading the criteria of Captain John Parkinson in his inquiry into the cardiac disabilities of solaiers on active service in your issue of July 22nd. If, indeed, we are to accept his sixth conclusion that the absence of abnormal physical signs in the heart of a soldier should not prevent his discharge from the Army if, under training or on active service he shows breathlessness or præcordial pain whenever he undergoes exertion well borne by his fellows ; then inasmuch as during the past 16 months some 1400 men who would correspond exactly to this description have been sent to me for an opinion and have invariably been returned to full duty, the amount of irreparable damage I would seem to have caused in this time may well be described as overwhelming!

If I have read his impressions correctly, Captain Parkinson is disposed to regard the symptoms of precordial pain and breathlessness on exertion as of not merely positive but supreme value, since he states that if such symptoms bear no relation to increase of pulse-rate on exertion, the latter is therefore valueless in judging the functional efficiency of the heart (Conclusion 4). Now, inasmuch as præcordial pain is entirely a subjective sensation, as a scientific standard it must surely be disregarded as of little, it any, worth. The importance to be attached to breathlessness on exertion is again, in my opinion, exceedingly slight. The breathlessness of which such patients complain - men without abnormal physical signs-is not by any means a true dyspnœa. It is shallow breathing, what is often termed lazy breathing, in fact a panting rather than an attempt at adequate respiration. It can be improved out of all recognition by the imposition of strenuous breathing exercises and demands a species of physical discipline to which the subject has been hitherto entirely unaccustomed. On the other hand, the reaction of the pulse-rate to violent exercise is an experiment which can be performed with perfect scientific exactness, and why such evidence of the heart's efficiency is not valid $I$ am quite unable to see. The malingerer will never have any difficulty in describing præcordial pain of all grades of intensity ; it is not so very difficult for him to simulate breathlessness by shallow respiration; but it needs some art to adjust his pulse-rate so that its return to the normal after exercise is unduly prolonged.

As I have stated, on an average three men per day are sent to me with a history that they cannot do the square or fall out on parade on account of pain in the heart and getting out of breath. I base $m y$ criterion of their cardiac efficiency on the rhythm, the size of the heart, and the reaction to violent exercise; and in the event of no abnormality being detected in any of these, I have no hesitation in excluding cardiac disease, and recommending such men for full duty whatever their symptoms, some of which will frequently disappear after dental treatment and the remainder by breathing exercises, persuasion, and reassurance. I frequently hear from medical officers to whom such recommendations have been made that the men have trained on without further trouble. Of course, such a description does not apply to all of Captain Parkinson's cases of "soldier's heart," some of which are clearly instances of organic cardiac disease. On the other hand, some are very evidently of the type to which I am referring-faint-hearted in the spiritual sense, who have never been able to play games, and tend to give up at the least discomfort upon unaccustomed exertion.

The question is one of great importance from two points of view. The invaliding of a large number of men who with persuasion might have made efficient soldiers is, of course, a serious loss to the active force. In the second place, the act of boarding out as unfit for military service on the grounds of some cardiac disability is a serious burden in their future life to men to whom such a diagnosis has no other meaning than heart disease with the constant danger of sudden death.

I am, Sir, yours faithfully, ADOLPHE ABRAHAMS,

Temporary Captain, R.A.M.C., Officer in Charge of Medical Division, Connaught Hospital, Aldershot.

Aldershot, July 22nd, 1916.

\section{CONDENSER DISCHARGES IN PHYSIO- LOGICAL EXPERIMENTS. \\ To the Editor of THE LANCET.}

SiR,-Dr. F. Hernaman-Johnson writes in your issue of July 15th on the subject of condenser discharges, and urges physiologists to abandon the use of an instrument so notoriously incapable of standardisation as the induction coil. If he will read the numerous papers on electrical stimulation which have been published by Nernst, Weiss, Hoorweg, Professor and Mme. Lapicque, Keith Lucas, A. V. Hill, and others, he will see that the merits of the condenser discharge have been recognised by physiologists for 15 years or more, and that it is by no means the most instructive or the most easily controlled form of stimulus. Indeed modern theories of stimulation have been arrived at mainly by the use of progressively increasing currents and of constant currents of short duration, though it is true that experiments with condensers have contributed materially to the present state of our knowledge. In many experiments it is quite unnecessary to vary the time relations of the discharge, and in this case the break shock of an induction coil is often the most satisfactory form of stimulus. If necessary it can be calibrated with very great accuracy. ${ }^{1}$ That the ordinary medical coil is incapable of standardisation is scarcely the fault of physiologists.

I am, Sir, yours faithfully,

E. D. AdriaN, M.B., B.C. Cantab.

Farnborough, Hants, July 18th, 1916.

\section{THE SHARPENING OF HOLLOW NEEDLES.}

\section{To the Editor of THE LANCET.}

SIR, - The following may be of use to your readers who have occasion to use hollow needles very much and have trouble with keeping them in repair. Procure through an ironmonger, or from a dealer in the carborundum wares, slip No. 89. Sharpen the needle by holding it on a support, such as a cork in a bottle, lumen upward, and shank level,

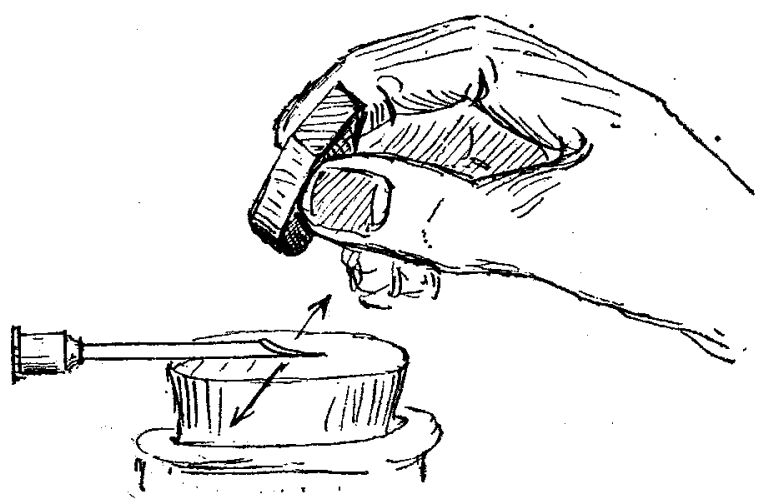

and rubbing it at right angles to the axis of the needle with the round edge of the slip till a hollow ground effect is obtained. Then lightly touch the back edges of the level on the flat of the stone to get rid of the rough edge and to obtain a sharp point. This answers excellently for all sizes and natures of hollow needles, from hypodermic sizes to aspirator or pneumothorax instruments. The slips cost 1s. $6 d$. When new they are rather too fierce, and may be dressed by soaking in a fairly viscous oil, such as liquid paraffin, for a few hours. After that they need only a light dressing of oil to make them do their work, and no oil at all for platinum iridium instruments. The sharp edge of the

1 Cf. Martin, American Juurnal of Physiology, 1912-1915. 